\title{
Integrating Radar Altimeters and Optical Imagery Data for Estimating Water Volume Variations in Lakes and Reservoirs (Case Study: Lake Nasser)
}

\author{
Hala M. Ebaid ${ }^{*}$, Medhat Aziz ${ }^{2}$ \\ ${ }^{1}$ Survey Research Institute, National Water Research Center, Giza, Egypt \\ ${ }^{2}$ Nile Research Institute, National Water Research Center, Cairo, Egypt \\ Email: ^hala_srif@yahoo.com
}

How to cite this paper: Ebaid, H.M. and Aziz, M. (2017) Integrating Radar Altimeters and Optical Imagery Data for Estimating Water Volume Variations in Lakes and Reservoirs (Case Study: Lake Nasser). Journal of Geographic Information System, 9, 648-662. https://doi.org/10.4236/jgis.2017.96041

Received: September 6, 2017

Accepted: November 28, 2017

Published: December 1, 2017

Copyright $\odot 2017$ by authors and Scientific Research Publishing Inc. This work is licensed under the Creative Commons Attribution International License (CC BY 4.0).

http://creativecommons.org/licenses/by/4.0/

(c) (i) Open Access

\begin{abstract}
Monitoring of variations in water for lakes and reservoirs is a requirement for meeting human needs and assessing ongoing climatic changes. However, regular gauging networks fail to provide the information needed for water volume data. The aim of this study is to evaluate an approach to estimate water volume variation for the southern part of Lake Nasser in Egypt without in-situ gauge measurements and bathymetry maps. Combination of both Hydroweb satellite altimetry and Landsat 8 satellite imagery data was used. As compared to in-situ water levels, satellite altimetry provided accurate water levels variations for Lake Nasser; the RMSE was $0.28 \mathrm{~m}$, with excellent agreement $\left(R^{2}\right.$ is 0.98). The lowest water level of altimetry database i.e. $174.57 \mathrm{~m}$ was used as a reference level for estimating water volumes variations for the study duration 8/2014-6/2015. All water altimetry levels were converted to differences of recorded water level above the lowest altimetry Level $(\Delta \mathrm{WL})$. Series of Landsat 8 imagery data were selected to extract surface areas corresponding to radar altimetry water levels dates. Areas- $\Delta \mathrm{WL}$ relationship model was established as a polynomial function: $A=f(\Delta \mathrm{WL})$, and therefore, the relationship of the water volume above the lowest water level for the study time $(\Delta \mathrm{V})$ and $\Delta \mathrm{WL}$ was obtained through the analytical integration of (Area- $\Delta \mathrm{WL}$ ) model. Another approach (Heron method) was also applied for estimating water volume variations. Validation of these two approaches showed that estimated water volume variations above reference water level using both methods i.e. integration and Heron agreed well with in-situ measurements of volume variation deduced from recent bathymetry map and in-situ water levels $\left(R^{2}\right.$ for both methods $=$
\end{abstract}


0.98). The RMSE for integration method is $323.89 \mathrm{MCM}$ and for Heron method was $318.09 \mathrm{MCM}$, being approximately $13.2 \%$ of the mean volume variations above the lowest reference water level for mean surface area $\approx 658 \mathrm{~km}^{2}$. Another byproduct for these approaches was the modeling for a remote detecting water level. Once the $\mathrm{F}(\mathrm{L})$ relationship is set up for a given region, future Landsat images can be utilized to track water levels freely of radar altimetry. Finally it can be concluded that remote sensing resources (satellites radar altimeters and optical satellite images) that are openly accessible these days represent a great opportunity to remotely monitor reservoir water capacity and help in examining and observing hydrological and water driven procedures.

\section{Keywords}

Radar Altimetry, Water Volume Change, Landsat 8, Lake Nasser, Egypt

\section{Introduction}

Regular and accurate monitor of variations in water for lakes and reservoirs would be necessary for equitable allocation of water and for a better understanding of the impact of climate change [1] [2] [3]. The traditional method of measuring water level is by gaging station installed near river mouths, bridges, weirs and sluices. Recently the use of gage stations has decreased around the globe [2] [4] [5] [6]. The stored water volume in reservoirs and lakes cannot be measured directly, and traditionally. A bathymetry map can be obtained from hydrologic surveys, using sonar sensors on ship transects to measure the underwater topography. But this kind of survey is time-consuming, labor intensive and costly [7]. Therefore, bathymetry maps are difficult to obtain for a given lake or reservoir. Satellite radar/laser altimetry is a technique that can be used to estimate water levels for water bodies. Both satellite radar and laser altimeters are profiling tools rather than imaging devices, which means that they can only record measurements along their ground tracks without the ability of a true global coverage [4] [8].

Different satellite altimetry missions are flying at different orbits, resulting in the different spatio-temporal coverage of lakes and reservoirs. Satellite radar altimetry has been utilized effectively to derive water levels of continental surface water forms; for example, inland seas, lakes, streams and wetlands. [2] [5]. At present, besides ICESat-GLAS, three other databases based on satellite radar altimetry for selected water bodies are operationally accessible. They are: 1) Global Reservoir and Lake Monitoring (GRLM) database; 2) the River Lake Hydrology (RLH) database by The River and Lake Project; and 3) the Hydroweb database. These four data bases involve the ICESat laser altimetry mission and five radar altimetry missions i.e. T/P (Topex/Poseidon), Jason-1, Jason-2 (also known as OSTM (Ocean Surface Topography Mission)), GFO (Geosat Fellow On) and ENVISAT (Environmental Satellite). 
Notwithstanding some limitations, altimetry is a method that needs a turned out possibility for hydrology science since that information would be freely accessible worldwide, and it is considered as the only source of information for most lakes in remote areas. Several satellite altimetry missions were launched since the late 1980s: GEOSAT (1986-1988), ERS-1 (1991-1996), Topex/Poseidon (1992-2005), ERS-2 (1995-), GFO (2000-2008), Jason-1 (2001-) Jason-2 (2008-) and ENVISAT (2002-). ERS-1, ERS-2 and ENVISAT have a 35-day temporal resolution (duration of the orbital cycle) and $70 \mathrm{~km}$ inter-track spacing at the equator. Topex/Poseidon, Jason-1 and Jason-2 have a 10-day orbital cycle and $350 \mathrm{~km}$ equatorial inter-track spacing. GEOSAT and GFO have a 17-day orbital cycle and $170 \mathrm{~km}$ equatorial inter-track spacing.

Recently, satellite radar altimetry was combined with satellite imagery to derive volume variations of surface water in large river basins such as the Negro River Basin [9] [10] [11], and the [12]. Few studies were carried out to derive variations of water volume in lakes using the combination of imagery and altimetry data. [13] reconstructed volume variations in the inland lake Big Aral Sea using the digital bathymetry model and water levels derived from T/P altimetry data. Reference [14] computed water storage changes in nine lakes of the Peach-Athabasca Delta, Canada using in-situ water levels and remotely sensed surface areas. Recently the GRACE satellite gravimetry has been used in combination with altimetry and satellite imagery data to study the variations of water volume in the very large inland water bodies, e.g. a study by [15]. These satellite altimetry databases are becoming attractive for operational applications in water resources management.

The purpose of the study is to evaluate an approach which combines two freely available Landsat images and radar altimeters data (processed into water levels), to estimate the water volume variations for the southern part of lake Nasser, without in situ measurements and bathymetry data. Two methods were applied for water volume variations estimation: Heron method and integration model method. These methods will help decision makers to estimate the relative water volume variations for the sake of water and environmental management rather than absolute values without in-situ water level measurements and bathymetric maps. The in-situ observed water levels and water volumes were used for assessing the accuracy of satellite altimetry databases and the estimated water volume variations.

\section{The Study Area}

Lake Nasser extends from southern Egypt to the northeast part of Sudan, with length of about $500 \mathrm{~km}$ and maximum width $35 \mathrm{~km}$. The total area surveyed is approximately 50,000 feddans. In general, the geographic boundary is between latitude $21^{\circ}$ and $24^{\circ} 30^{\prime}$ north and longitude $31^{\circ} 30^{\prime}$ and $33^{\circ}$ east. This research is limited to the Egyptian portion of Lake Nasser that extends along $50 \mathrm{~km}$ from Sudan border (Figure 1). 


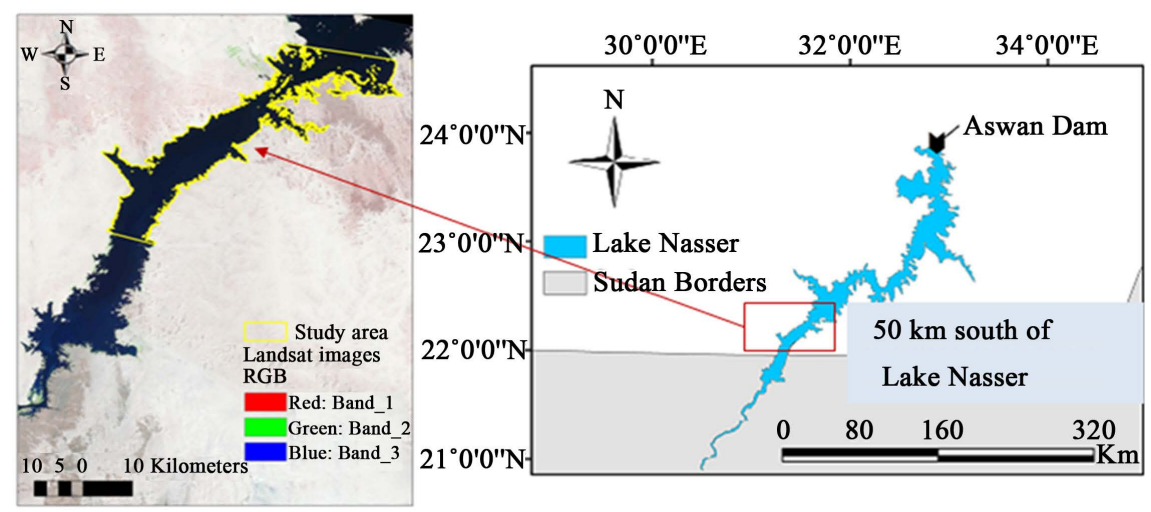

Figure 1. Study area in Lake Nasser.

\section{Data Sets}

\subsection{Daily Measured Water Levels}

Measurements of water level between August, 2014 and June 2015at one gauging station for Lake Nasser were obtained from Nile Research Institute (NIR) database for assessment purpose. Figure 2 demonstrates measured water levels trend. With standard deviation about 1.4 for this short duration between (2014-2015).

The corresponding Surface regions and also water volumes were computed with the use of surface volume tool under ArcGIS environment. Thus being based on a recently created bathymetry map obtained from hydrologic surveys, using multi-beam echo sounder which is a device used to determine the depth of water and the nature of the water stream bed (underwater topography). Figure 3 shows the multi-beam acquisition software and the diagram of multi beam scanning area [16]. Figure 4 demonstrates the resulted bathymetry level points for the study area

\subsection{Radar Altimetry Data}

Hydroweb available satellite water height comprised different satellite altimetry: Topex/Poseidon, Jason 2, Gfo, Envisat, Saral. These data were obtained for free from [17]. Figure 5 demonstrates a snapshot for the database of Lake Nasser that includes the near real water level and surface area, water volume through the years 1992 to 2016. While Figure 6 shows the trend of radar altimetry water levels through only 2014-2015 period. Both data (text and graphs) were downloaded from Hydroweb which include: (decimal year, date, time, height above surface of reference, standard deviation, area in $\mathrm{km}^{2}$, volume with respect to volume of the first date in $\mathrm{km}^{3}$, Flag).

\subsection{Optical Satellite Images for Surface Area Estimation}

Landsat 8 data with cell size of $30 \mathrm{~m}$ were used (for criteria of suitability and low cost) to derivate surface areas for the lakes and reservoirs. Landsat8 data were downloaded from [18]. The dates of altimetry-derived water levels and the satellite images should be coincide exactly. However, most of the time this was not 


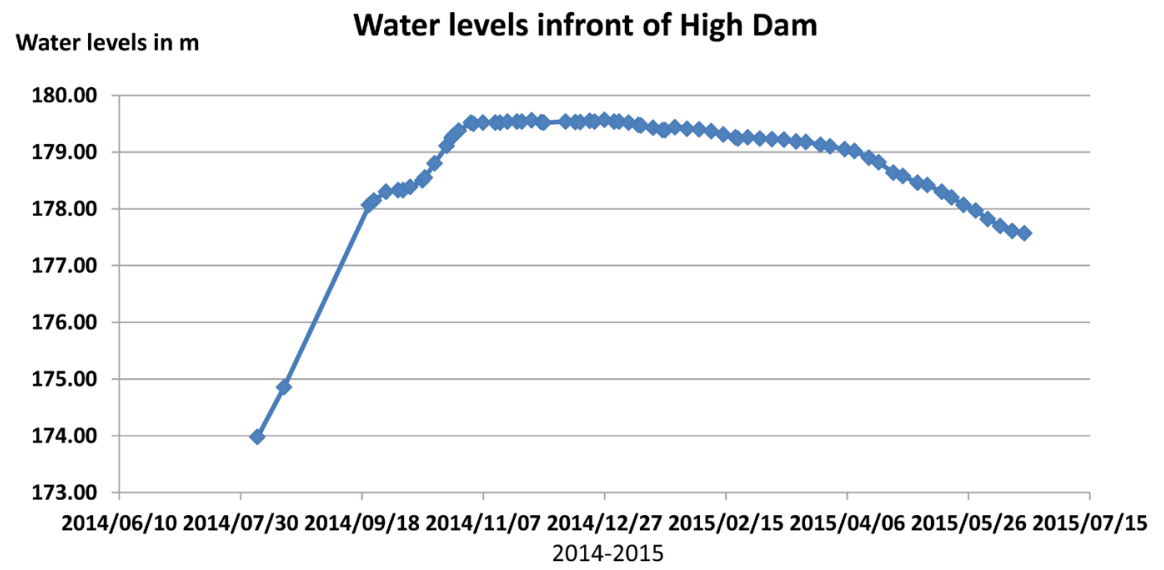

Figure 2. Measured water levels data.

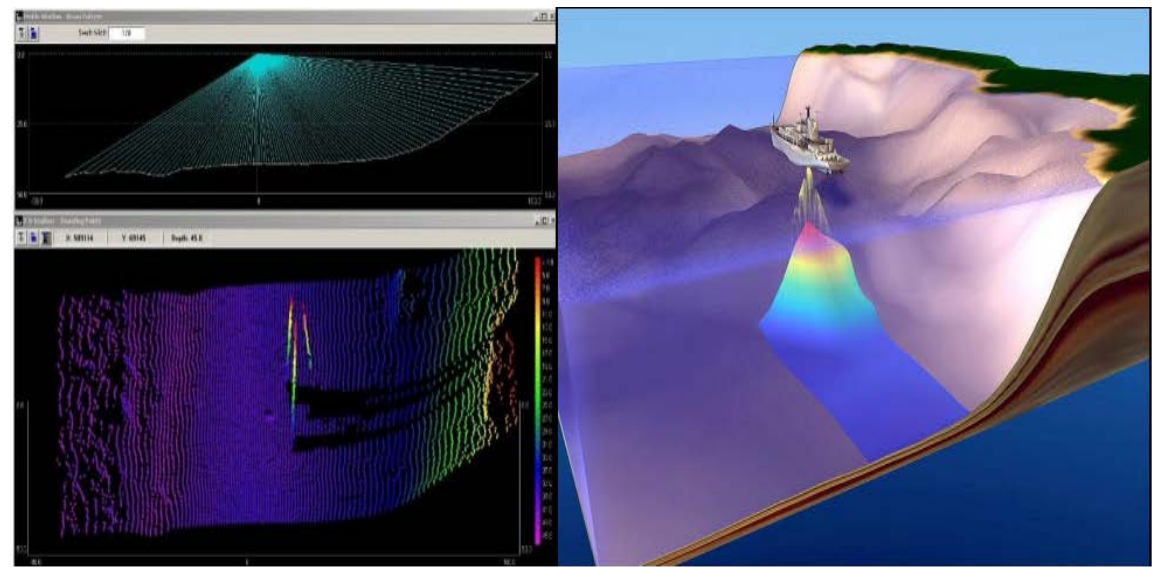

Figure 3. The multi-beam echo sounder [16].

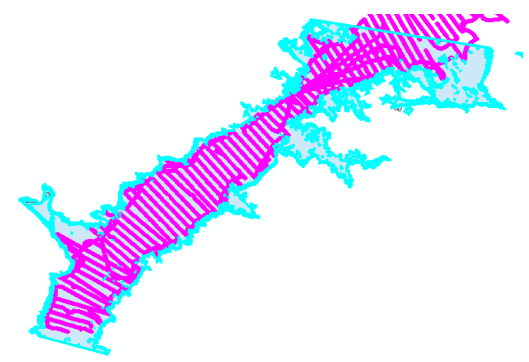

Figure 4. Bathymetry level points for the study area (NRI data).

the case; firstly because of the different crossover repeated cycles of Landsat (16 days) and altimeter satellites (10 - 35-day or campaign mode) and secondly, some Landsat data could not be used because cloud cover affected the quality of the data. An analysis of daily in-situ measurements showed that variations in water levels during a short period (five days) are minimal. In this study: Landsat images for the best 2 days before or after the dates of altimetry-derived water levels were used to derive water surface areas at the corresponding water levels. Two observation time series were used: first, lake surface areas, which extracted from Landsat 8 and second, water levels which deduced from radar altimeters. 


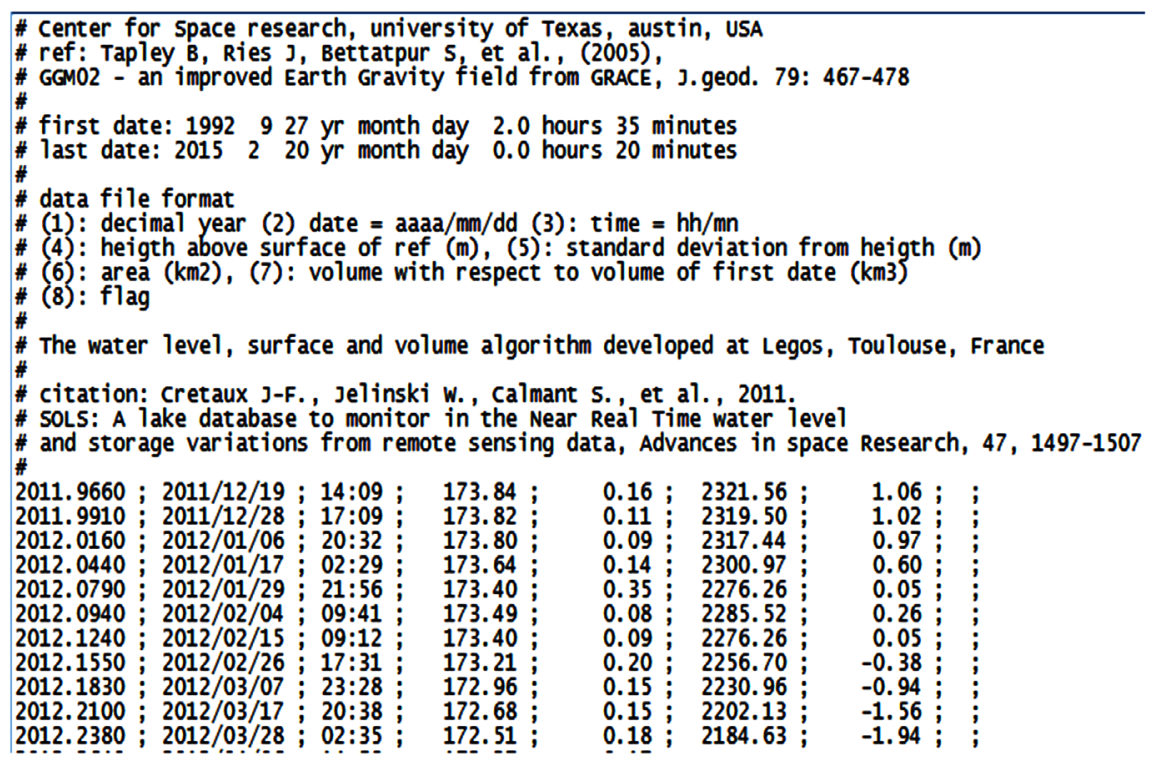

Figure 5. Snap shot of altimeter water levels data which is download from Hydroweb site.

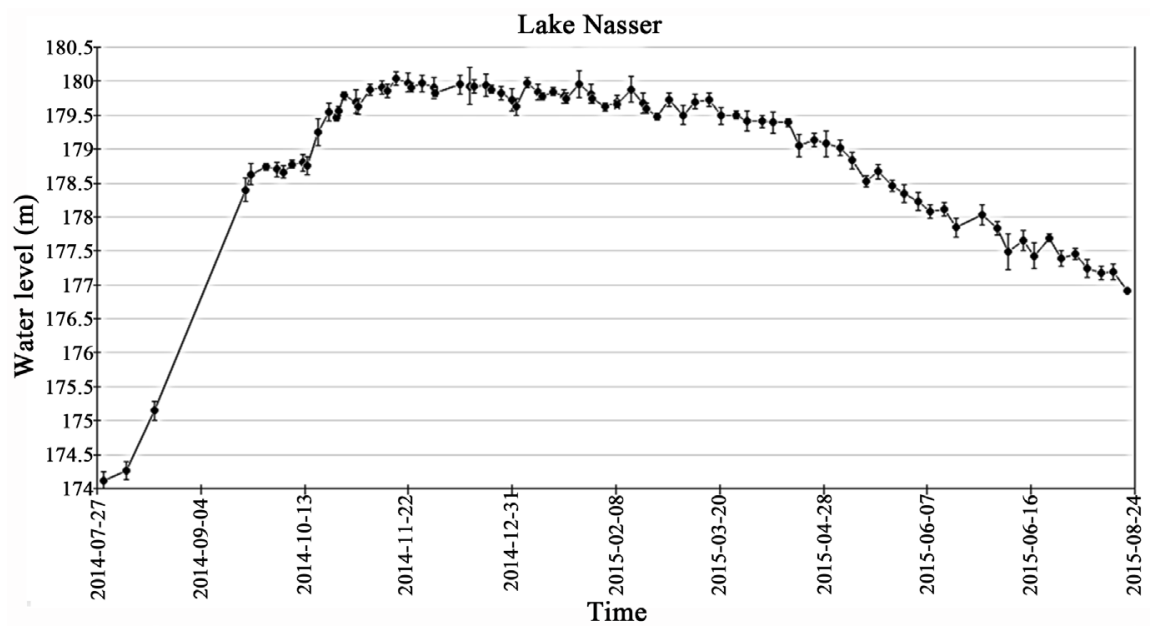

Figure 6. Radar altimetry water heights graph download from Hydroweb (2014-2015).

\section{Methodology}

Landsat 8 Satellite data were selected to match the dates of altimetry-derived water levels. and these images were geometry corrected and were subset to the domain of collected in situ bathymetry map obtained from recent hydrologic surveys using sonar sensors by NIR (in 2013). Classification technique was used to determine the surface area of Lake Nasser study area. This method of classification helps to distinguish accurately the water boundary of the study area in Lake Nasser, where the nature of the land cover of the south part of Egypt is mostly desert and water (Figure 7).

\subsection{Water Volume Variation Estimation}

Two methods for water volume variation estimation were adopted in this study, and they are described as follows. 

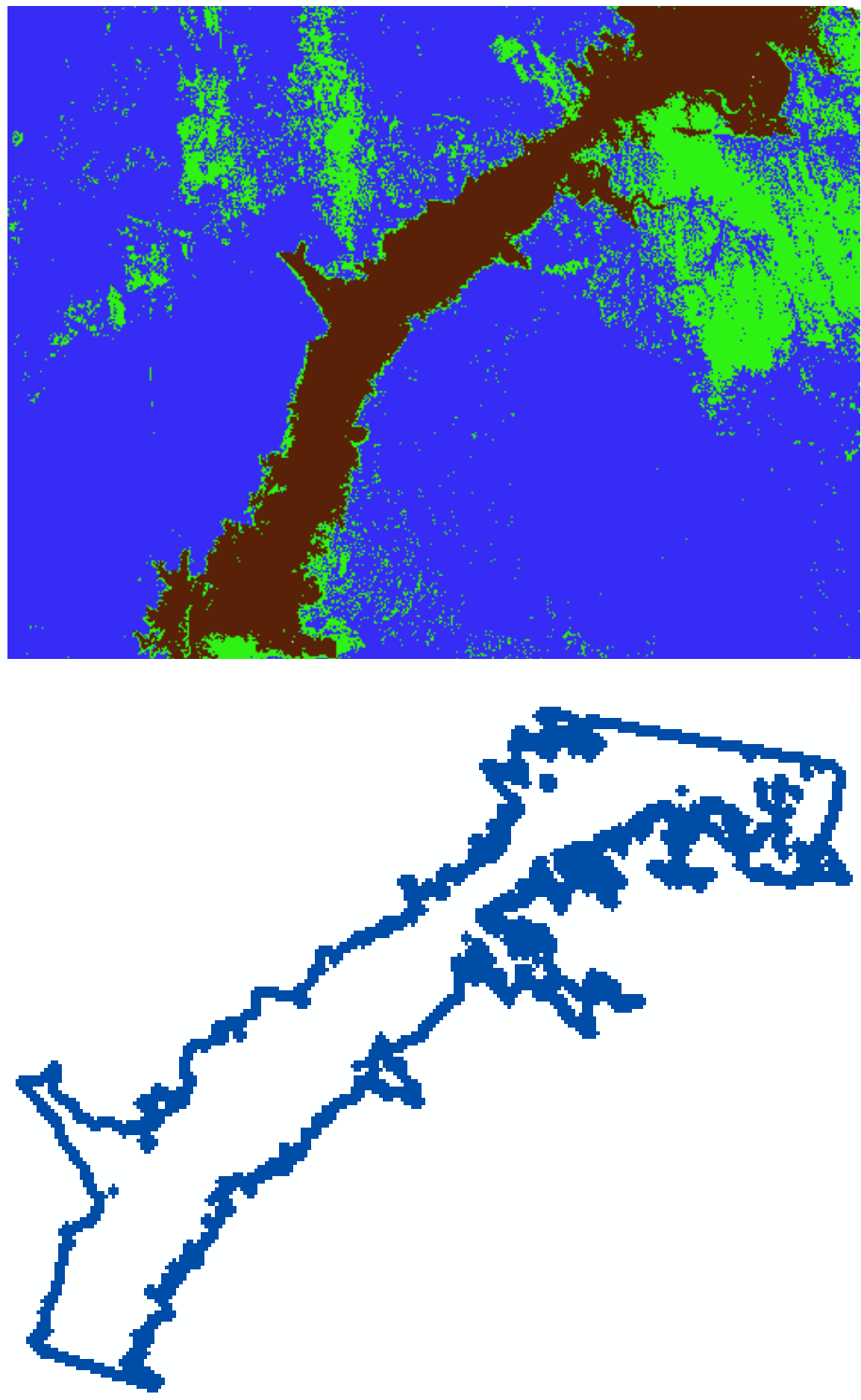

Figure 7. Resulted classes from unsupervised classification \& Lake Nasser study area.

\subsubsection{Analytical Integration}

This method is a precise lake volume derivation based on polynomial function fitting, $F$, using scatter between the surface area $(A)$ and water level $(L)$ measurements which consider as a robust fitting relation. Since any increase in water level must be accompanied by increase in water area. $A=F(L)$ and volume can be obtained by simply integrating (Equation (1)). 


$$
\Delta V=\int_{l 1}^{l 2} f(L) \mathrm{d} l
$$

The approach is useful if the full range of water levels cannot be observed. In other words the variations from reference level of water will be studied and evaluated as follows:

As stated by [19], the total volume $(V)$ of water depends on a specific constant minimum volume of water contained in lakes $\left(V_{\text {fixed }}\right)$, and a variable component that varies with the water levels ( $V_{\text {var }}$ ) as describe in Equation (2):

$$
V=V_{\text {fix }}+V_{\text {var }}
$$

$V_{\text {fix }}$ refers to the water stored between a certain constant water level and the bottom. The single value for $V_{\text {fix }}$ can be obtained from topographic maps before a reservoir is constructed or rarely from bathymetric maps. Determination of $V_{\text {fix }}$ has several difficulties. The underlying topography is uneven and it fluctuates significantly; thereby increasing error factors. In addition, the underlying topography changes continuously and elevations increase due to sedimentation and other human activities [7] [20]. The determination of $V_{\mathrm{var}}$ is for practical purposes more appealing.

The lowest water level derived from satellite altimetry during the study period can be set as reference level to separate $V_{\text {fix }}$ (which disregarded in the scope of this study) and $V_{\text {var }}$. The resulting water volume $V_{\text {var }}$ is referred to as water volume above the lowest water level i.e. 174.57 in this study. The lowest water level value in satellite altimetry data was subtracted from all water level values obtained from altimetry data to obtain the variation of water level above the lowest water level $(\Delta \mathrm{WL})$. The function relate $(\Delta \mathrm{WL})$ and corresponding lake surface area (area- $\Delta \mathrm{WL}$ ) was established using regression analysis. Because the water volume is the integration of the functional relationship between lake surface area and water level, thereby the $(\Delta \mathrm{WV}-\Delta \mathrm{WL})$ relationship, where $\Delta \mathrm{WV}$ is the volume variation above lowest reference water level, can be obtained by analytically integrating function of (area- $\Delta \mathrm{WL}$ ) with the condition that $\Delta \mathrm{WV}$ is equal to zero when $\Delta \mathrm{WL}$ is zero. Assume that the area- $\Delta \mathrm{WL}$ relation can be described as a polynomial function for example: $A=f(L)=a L^{2}+b L+c$, where $A$ is the surface area in $\mathrm{km}^{2}, L$ is $\Delta \mathrm{WL}$ in $\mathrm{m}$, and $a, b, c$ are coefficients determined by regression analysis. Then the $(\Delta \mathrm{WV}-\Delta \mathrm{WL})$ function which is the integration of $f(L)$ against $\mathrm{d} L$ can be written as: $\Delta \mathrm{WV}=\int f(L) \mathrm{d} L=a L^{3} / 3+b L^{2} / 2+c L+d$, where $\mathrm{d}$ can be solved as 0 given the condition $(\Delta \mathrm{WV}=0$ when $L=0)$. The resulting equation can be used to convert the time-series of $(\Delta \mathrm{WL})$ to $(\Delta \mathrm{WV})$ for the analysis of volume variations in lakes or reservoirs.

\subsubsection{Heron Method}

Pyramidal frustum volume was derived 2000 years ago by Heron (Greek mathematician, native of Alexandria, 10-70 AD) as in Equation (3):

$$
V=((L 1-L 2) / 3) *(A 1+A 2+(\sqrt{A 1 * A 2}))
$$


Two water levels: $L 1$ and $L 2$ with corresponding surface areas $A 1$ and $A 2$ are using in this relation and limnologists are still using Formula (3) to compute the volume of lakes.

\section{Results and Discussions}

Comparison between measured water level time-series and those of radar altimetry must be first evaluated to ensure the accuracy of radar altimetry water levels data (for the period 2014 to 2015), to be based for water volume variation estimation. The resulted correlation coefficient $R^{2}=0.98$ and RMSE $=28 \mathrm{~cm}$ (Figure 8).

The next two figures demonstrate the relations between: surface areas (in $\mathrm{km}^{2}$ ) deduced from optical satellite images and 1-radar altimetry and 2-measured water levels. $R^{2}$ for the first relation was 0.96 , and for the second was 0.99 . These excellent correlation values give a confidence of the deduced surface areas from the satellite images (Figure 9 and Figure 10).

The relationship between resulted $(\Delta \mathrm{WL})$ which was deduced from altimetry data and corresponding surface area (Area- $\Delta \mathrm{WL}$ ) was established using regression analysis for the study period (from 8/2014 till 6/2015). This relation was

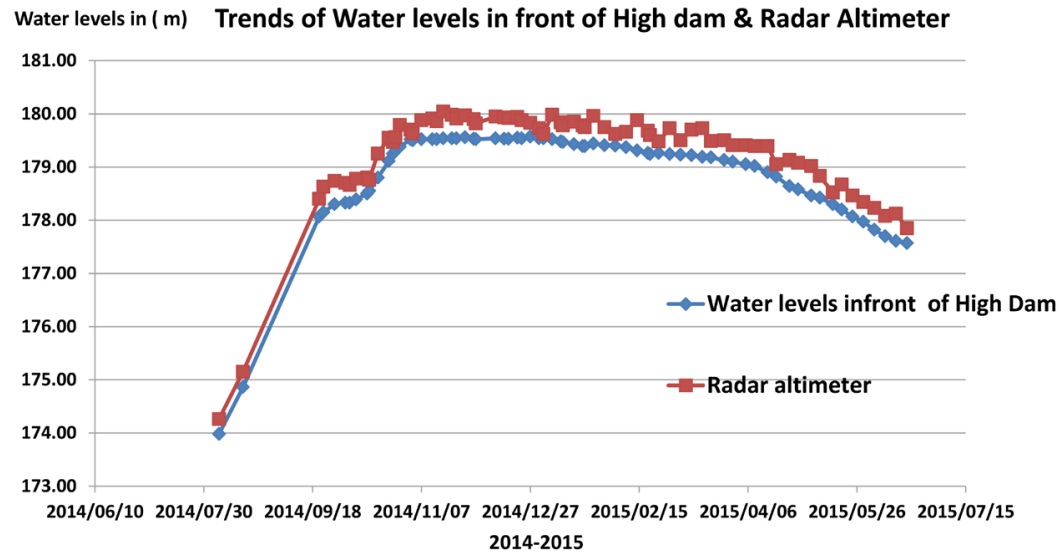

Figure 8. Comparison between measured water levels and satellite altimetry water levels.

Relation between areas $\left(\mathrm{km}^{2}\right)$ and Water levels_HD(m)

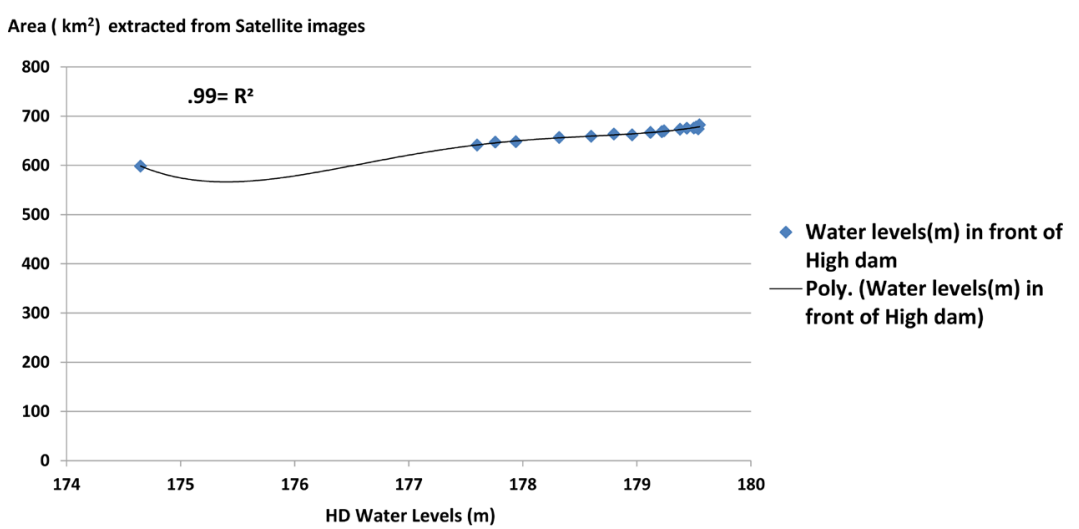

Figure 9. Relation between surface areas and in-situ water levels. 


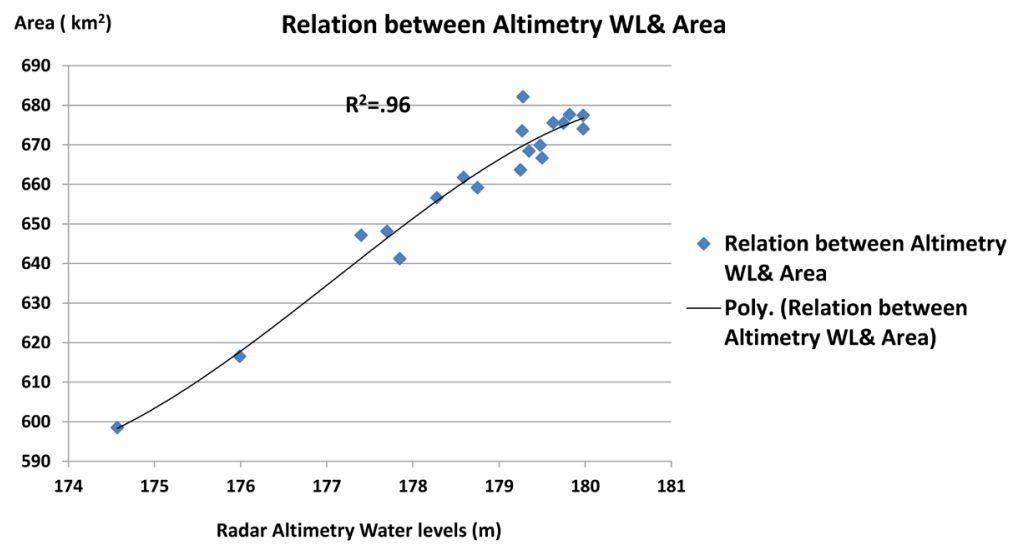

Figure 10. Relation between surface area and satellite altimetry water levels.

described as a fourth-polynomial function (Equation (4)) with $R^{2}=0.979$ (Figure $11)$.

Area $=0.223(\Delta \mathrm{WL})^{4}-2.644(\Delta \mathrm{WL})^{3}+9.693(\Delta \mathrm{WL})^{2}+4.236(\Delta \mathrm{WL})+598.4(4)$

Determination of volume variation (using integration model) relative to minimum altimetry water level (as reference) can be deduced by Integration of $f(L)$ against $\mathrm{d} l$, and can be developed as follows:

$$
\begin{aligned}
& \Delta \mathrm{WV}=\int \text { Aread } l=\int F(\Delta \mathrm{WL}) \mathrm{d} l \\
& \begin{aligned}
&=\int 0.223(\Delta \mathrm{WL})^{4}-2.644(\Delta \mathrm{WL})^{3}+9.693 / 2(\Delta \mathrm{WL})^{2}+4.236(\Delta \mathrm{WL})+598.4 \\
& \Delta \mathrm{WV}= 223 / 5(\Delta \mathrm{WL})^{5}-2.644 / 4(\Delta \mathrm{WL})^{4}+9.693 / 3(\Delta \mathrm{WL})^{3} \\
&+4.236 / 2(\Delta \mathrm{WL})^{2}+598.4(\Delta \mathrm{WL})+\text { constant } \\
&(\text { constant }=0 \text { at } \Delta \mathrm{WV}=0 \text { at reference level })
\end{aligned}
\end{aligned}
$$

Estimated $\triangle \mathrm{WV}$ in million cubic meters (MCM) was calculated by substituting the corresponding $\Delta \mathrm{WL}$ in Equation (6). The ideal way to verify the estimated water volume variations would be a test on a lake, were there is both long-term satellite coverage and simultaneous measured ground truth obtained by sonar bathymetry and gauges water level. Unfortunately the available ground truth data concerning the water levels are limited to (2014-2015), in spite of the availability of a reasonable number of Landsat images matching the times of radar altimetry data. To validate the resulted estimated water volumes variations, the measured water volumes were converted to $\triangle \mathrm{WV}$ measured as estimated water volumes variations. This conversion was carried out by subtracting the water volume value for the same date that the lowest altimetry water level occurred from all measured water volumes values. Other approach was applied to estimate water volumes variations (based on altimetry water levels and satellite surface areas) by using Heron method, which is described in Equation (3). The estimated $\Delta \mathrm{WV}$ using Integration method, Heron method, and measured $\Delta \mathrm{WV}$ values were demonstrated in Table 1. $R^{2}$ and RMSE were determined to validate the estimated $\Delta \mathrm{WV}$ for the two methods.

Root mean square errors for estimated $\Delta \mathrm{WV}$ using integration and Heron 


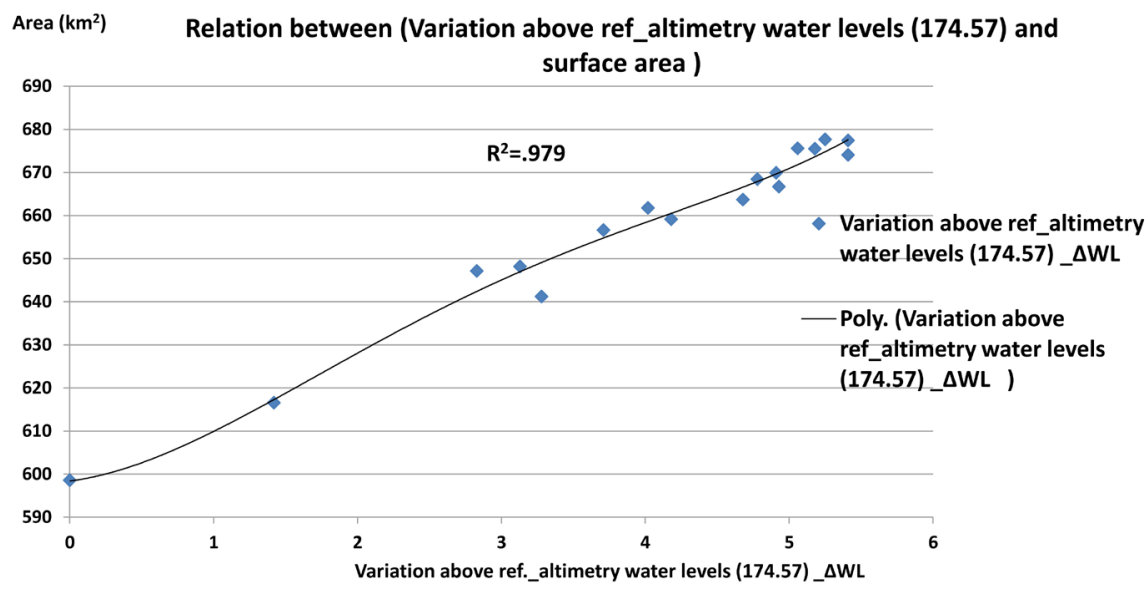

Figure 11. Relation between surface area \& altimetry $\Delta \mathrm{WL}$.

Table 1. Estimated and measured $\triangle \mathrm{WV}$ in MCM.

\begin{tabular}{ccc}
\hline $\begin{array}{c}\text { Estimated } \Delta \mathrm{V} \text { in } \mathrm{MCM} \\
\text { using integration model }\end{array}$ & $\begin{array}{c}\text { Estimated } \Delta \mathrm{V} \text { in } \mathrm{MCM} \\
\text { using Heron method }\end{array}$ & Measured $\Delta \mathrm{V}$ in MCM \\
\hline 0.0000 & 0.0000 & 0.0000 \\
864.1219 & 884.1889 & 914.5171 \\
1753.0406 & 1762.1512 & 1850.1118 \\
1946.1168 & 1950.4932 & 1941.5877 \\
2043.1615 & 2032.7182 & 1786.4655 \\
2323.1938 & 2327.4096 & 2201.2364 \\
2526.7296 & 2532.0249 & 2582.0204 \\
2632.3074 & 2627.4616 & 2341.8795 \\
2964.4716 & 2952.1895 & 2480.8515 \\
3031.2980 & 3026.3750 & 2826.7853 \\
3118.3619 & 3112.3298 & 2730.7379 \\
3131.7751 & 3117.2149 & 2653.7375 \\
3219.0814 & 3221.5179 & 2936.5240 \\
3299.8543 & 3297.6047 & 2885.6361 \\
3347.0512 & 3347.7846 & 2956.5289 \\
3455.1449 & 3440.2604 & 2927.7132 \\
3455.1449 & 3449.1731 & 2937.7575
\end{tabular}

methods were 323.98 , and 318.09 MCM respectively and $R^{2}=0.98$ for both methods (Figure 12 and Figure 13).

Another byproduct is proposed for this study; Once the $F(\mathrm{~L})$ relationship is established for a given area, hence future Landsat images can be used to track water levels independently of radar altimetry.

It is important to mention that these results were consistent with those deduced by [21] for Lake Tana in Ethiopia $\left(R^{2}=0.99\right)$ for both relations: between water levels and areas deduced from Landsat satellite images; and those between 


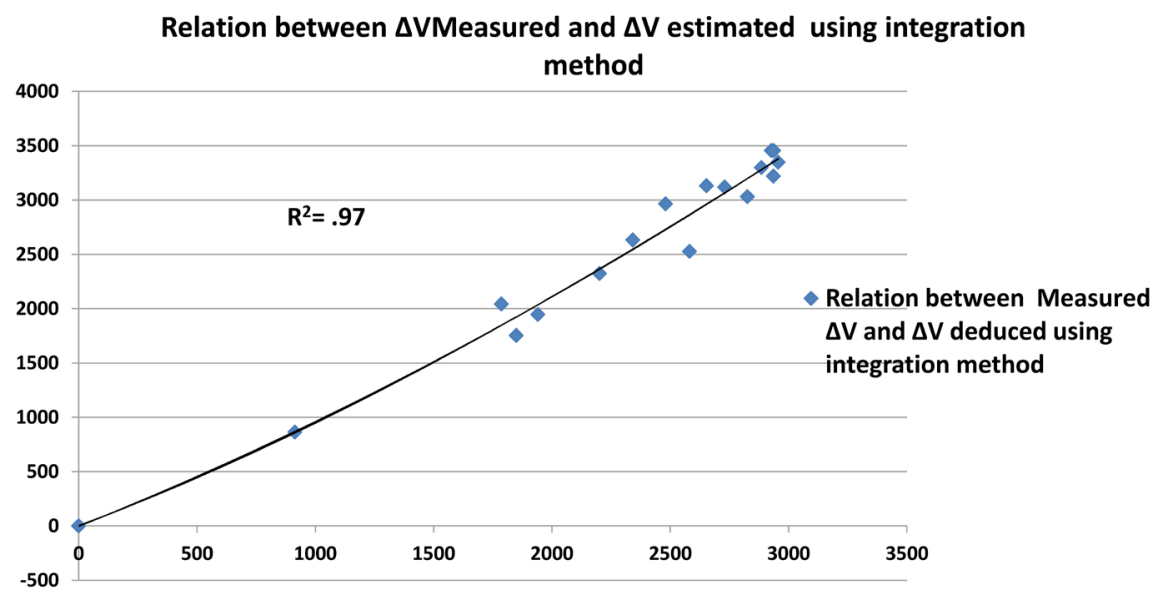

Figure 12. Relation between estimated $\Delta \mathrm{WV}$ using integration method and measured $\Delta \mathrm{WV}$.

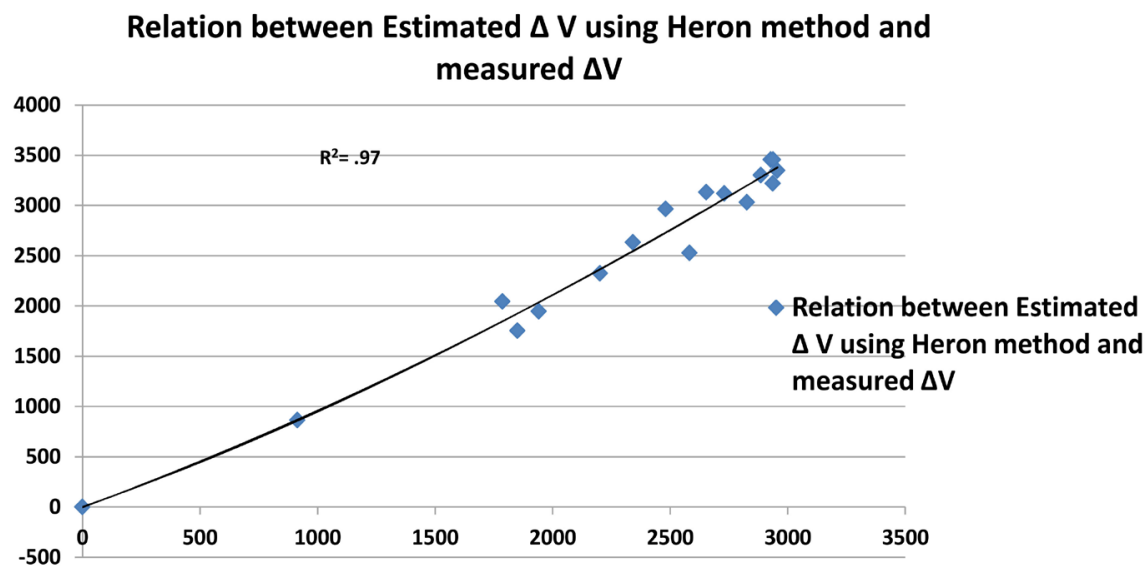

Figure 13. Relation between estimated $\Delta \mathrm{WV}$ using Heron method \& measured $\Delta \mathrm{WV}$.

water level and water volumes. Also the validation of the study which carried out by [19] for Lake Mead (U.S.A.), Lake Tana (Ethiopia), and Lake IJssel (The Netherlands) showed that the estimated water volumes agreed well with in-situ measurements ( $R^{2}$ ranged from 0.95 to 0.99 ) and the root mean square error (RMSE) was within $4.6 \%$ to $13.1 \%$ of the mean volumes of in-situ measurements, which is consistent with the evaluation results of Lake Nasser study.

Other issues need to be illustrated: 1$)$ The $(\Delta \mathrm{WV}-\Delta \mathrm{WL})$ relationship is site-specific and radar altimetry database-specific, and can be used, also to convert water levels from the altimetry databases directly into water volumes above the identified minimum reference level for lake Nasser; 2) From Table 1, the calculated volume variations using Integration method were approximately equal those calculated using Heron method, and this is considered as important indicator of high confidence in using the polynomial integration method; 3) The accuracy of water volume variations are affected by the relation between water levels and corresponding surface areas, as when water levels increase, the surface area deduced from satellite images specially at Khors regions will increase more than the middle stream of the 
lake which may cause unreal water volumes variations at the lake boundary, hence high water levels may cause errors in calculations of volume variation by applying the polynomial relation between water levels and surface areas as it is clear from Table 1, when water levels increase the difference between in situ volume variations and those estimated from integration, Heron methods increase; 4) In this work, the measured water levels were limited to short duration time (2014-2015) so the integration model may changes for long duration and this must be investigated; 5) The surface areas which deduced from satellite images gain some errors due to: atmospheric effects, low spatial resolutions, and the conflict between dates of altimetry data sets and satellite images acquisition dates, and these errors can affect the deduced volume variations accuracy. In general, the integration model needs to be further studied to be more generalized due to site specific and time. Also the future work should focus on improving the model performance.

\section{Conclusions}

Estimating water volume variations relative to reference water level for the southern part of Lake Nasser in Egypt were determined and evaluated using available free Landsat and radar altimeter datasets, instead of using in-situ water gauge and bathymetry maps. Two approaches were examined for water volume variation estimation: The first method based on Areas- $\Delta \mathrm{WL}$ relationship model ( $\Delta \mathrm{WL}$ is the difference between radar altimetry water levels and the lowest water level during the study time). Areas- $\Delta \mathrm{WL}$ relationship model was established as a polynomial function: Area $=f(\Delta W L)$, hence, the relationship of the water volume variations above the lowest water level for the study time, i.e. $(\Delta \mathrm{V}-\Delta \mathrm{WL})$ was obtained through the analytical integration of Areas- $\Delta \mathrm{WL}$ relationship model. The second method was performed by applying Heron equation:

$$
\Delta V=((L 1-L 2) / 3) *(A 1+A 2+(\sqrt{A 1 * A 2}))
$$

Validation of these two approaches showed that: Integration model and $\mathrm{He}-$ ron agreed well with in-situ measurements of volume variation deduced from recent bathymetry map and in-situ water levels $\left(R^{2}\right.$ for both methods $\left.=0.98\right)$ and RMSE for integration method $=323.89 \mathrm{MCM}$, while for Heron method, RMSE $=$ $318.09 \mathrm{MCM}$, and these RMSE values were approximately $=13.2 \%$ of the mean volume variation above lowest reference water level for the study period, for mean surface area $\approx 658 \mathrm{~km}^{2}$. The initial results for this specific geographic area of Lake Nasser showed promising approaches for monitoring Lake Nasser water volume variation. Further tests are needed to firmly prove these techniques in order to generalize the relationship model of the water volume variations above the lowest water level $(\Delta \mathrm{V}-\Delta \mathrm{WL})$ to be valid for all geographic areas of Lake Nasser, and to enhance the accuracy. In addition, further improvements are expected when additional data from current and future satellite missions are integrated. 


\section{References}

[1] Birkett, C.M. (1995) The Contribution of TOPEX/POSEIDON to the Global Monitoring of Climatically Sensitive Lakes. Journal of Geophysical Research-Oceans, 100, 25179-25204. https://doi.org/10.1029/95JC02125

[2] Crétaux, J.F. and Birkett, C. (2006) Lake Studies from Satellite Radar Altimetry. Comptes Rendus Geosciences, 338, 1098-1112.

https://doi.org/10.1016/j.crte.2006.08.002

[3] Crétaux, J.F., Jelinski, W., Calmant, S., Kouraev, A., Vuglinski, V., Berge-Nguyen, M., et al. (2011) SOLS: A Lake Database to Monitor in the Near Real Time Water Level and Storage Variations from Remote Sensing Data. Advances in Space Research, 47, 1497-1507. https://doi.org/10.1016/j.asr.2011.01.004

[4] Alsdorf, D.E., Rodriguez, E. and Lettenmaier, D.P. (2007) Measuring Surface Water from Space. Reviews of Geophysics, 45, RG2002.

https://doi.org/10.1029/2006RG000197

[5] Calmant, S., Seyler, F. and Crétaux, J.F. (2008) Monitoring Continental Surface Waters by Satellite Altimetry. Surveys in Geophysics, 29, 247-269. https://doi.org/10.1007/s10712-008-9051-1

[6] Frappart, F., Calmant, S., Cauhope, M., Seyler, F. and Cazenave, A. (2006) Preliminary Results of ENVISAT RA-2-Derived Water Levels Validation over the Amazon Basin. Remote Sensing of Environment, 100, 252-264.

https://doi.org/10.1016/j.rse.2005.10.027

[7] Peng, D.Z., Guo, S.L., Liu, P. and Liu, T. (2006) Reservoir Storage Curve Estimation Based on Remote Sensing Data. Journal of Hydrologic Engineering, 11, 165-172. https://doi.org/10.1061/(ASCE)1084-0699(2006)11:2(165)

[8] Birkett, C.M. and Beckley, B. (2010) Investigating the Performance of the Jason-2/ OSTM Radar Altimeter over Lakes and Reservoirs. Marine Geodesy, 33, 204-238. https://doi.org/10.1080/01490419.2010.488983

[9] Frappart, F., Seyler, F., Martinez, J.M., Leon, J.G. and Cazenave, A. (2005) Floodplain Water Storage in the Negro River Basin Estimated from Microwave Remote Sensing of Inundation Area and Water Levels. Remote Sensing of Environment, 99, 387-399. https://doi.org/10.1016/j.rse.2005.08.016

[10] Frappart, F., Papa, F., Famiglietti, J.S., Prigent, C., Rossow, W.B. and Seyler, F. (2008) Interannual Variations of River Water Storage from a Multiple Satellite Approach: A Case Study for the Rio Negro River Basin. Journal of Geophysical Research, 113, D21104.

[11] Frappart, F., Papa, F., Guntner, A., Werth, S., da Silva, J.S., Tomasella, J., Seyler, F., Prigent, C., Rossow, W.B., Calmant, S. and Bonnet, M.-P. (2011) Satellite-Based Estimates of Groundwater Storage Variations in Large Drainage Basins with Extensive Floodplains. Remote Sensing of Environment, 115, 1588-1594.

https://doi.org/10.1016/j.rse.2011.02.003

[12] Liu, T., Tseng, H., Shum, K., YiLiu, C., Kuo, Y., Ganming, L., Jia, Y. and Shang, K. (2016) Assessment of the Impact of Reservoirs in the Upper Mekong River Using Satellite Radar Altimetry and Remote Sensing Imageries. Remote Sensing Journal, 8 , 367.

[13] Cretaux, J.-F., Kouraev, A.V., Papa, F., Berge Nguyen, M., Cazenave, A., Aladin, N.V. and Plotnikov, I.S. (2005) Water Balance of the Big Aral Sea from Satellite Remote Sensing and in Situ Observations. Journal of Great Lakes Research, 31, 520-534. https://doi.org/10.1016/S0380-1330(05)70281-1 
[14] Smith, L.C. and Pavelsky, T.M. (2009) Remote Sensing of Volumetric Storage Changes in Lakes. Earth Surface Processes and Landforms, 34, 1353-1358. https://doi.org/10.1002/esp.1822

[15] Singh, A., Seitz, F. and Schwatke, C. (2012) Inter-Annual Water Storage Changes in the Aral Sea from Multi-Mission Satellite Altimetry, Optical Remote Sensing, and GRACE Satellite Gravimetry. Remote Sensing of Environment, 123, 187-195. https://doi.org/10.1016/j.rse.2012.01.001

[16] Shafik, N.M. (2016) Updating the Surface Area and Volume Equations of Lake Nasser using Multi Beam System. 19th International Water Technology Conference, 21-23 April 2016.

[17] Radar Water Level Data for Lakes, Nasser Lake. http://hydroweb.theia-land.fr

[18] Archived Landsat Data for Lake Nasser Region. http://Earthexplorer.usgs.gov

[19] Zheng, D. and Bastiaanssen, W.G.M. (2013) Estimating Water Volume Variations in Lakes and Reservoirs from Four Operational Satellite Altimetry Databases and Satellite Imagery Data. Remote Sensing of Environment, 134, 403-416.

[20] Feng, L., Hu, C.M., Chen, X.L., Li, R.F., Tian, L.Q. and Murch, B. (2011) MODIS Observations of the Bottom Topography and Its Inter-Annual Variability of Poyang Lake. Remote Sensing of Environment, 115, 2729-2741.

https://doi.org/10.1016/j.rse.2011.06.013

[21] Dost, R.J.J., Maathuis, B.H.P. and Kaba Ayana, E. (2007) Validation Techniques for Radar Altimeter Measurements over Ungauged in Land Waters in the Ethiopian Highland and Rift Valley. 2nd Space for Hydrology Workshop Conference. 